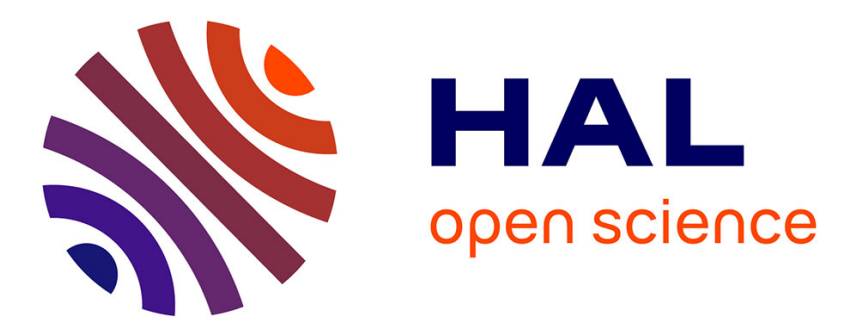

\title{
Management of the irradiated N0-neck during salvage pharyngo-laryngeal surgery
}

Paul Mazerolle, Philippe Gorphe, Benjamin Vairel, Agnès Dupret Bories, Stéphane Temam, Léonor Chaltiel, Sébastien Vergez

\section{To cite this version:}

Paul Mazerolle, Philippe Gorphe, Benjamin Vairel, Agnès Dupret Bories, Stéphane Temam, et al.. Management of the irradiated N0-neck during salvage pharyngo-laryngeal surgery. EJSO - European Journal of Surgical Oncology, 2020, 46 (6), pp.1059-1065. 10.1016/j.ejso.2020.01.011 . hal-03202758

\section{HAL Id: hal-03202758 \\ https://hal.science/hal-03202758}

Submitted on 20 Apr 2021

HAL is a multi-disciplinary open access archive for the deposit and dissemination of scientific research documents, whether they are published or not. The documents may come from teaching and research institutions in France or abroad, or from public or private research centers.
L'archive ouverte pluridisciplinaire HAL, est destinée au dépôt et à la diffusion de documents scientifiques de niveau recherche, publiés ou non, émanant des établissements d'enseignement et de recherche français ou étrangers, des laboratoires publics ou privés. 


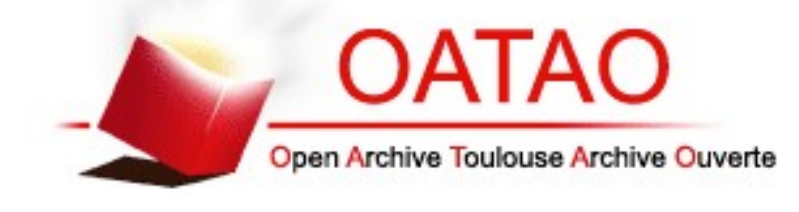

\section{Open Archive Toulouse Archive Ouverte}

OATAO is an open access repository that collects the work of Toulouse researchers and makes it freely available over the web where possible

This is an author's version published in: https://oatao.univ-toulouse.fr/27611

Official URL :

https://doi.org/10.1016/j.ejso.2020.01.011

To cite this version:
Mazerolle, Paul and Gorphe, Philippe and Vairel, Benjamin and
Dupret Bories, Agnès and Temam, Stéphane and Chaltiel, Léonor
and Vergez, Sébastien Management of the irradiated N0-neck
during salvage pharyngo-laryngeal surgery. (2020) European
Journal of Surgical Oncology, 46 (6). 1059-1065. ISSN 0748-7983

Any correspondence concerning this service should be sent to the repository administrator: tech-oatao@listes-diff.inp-toulouse.fr 


\title{
Management of the irradiated N0-neck during salvage pharyngo- laryngeal surgery
}

\author{
Paul Mazerolle ${ }^{\mathrm{a}}$, Philippe Gorphe ${ }^{\mathrm{b}}$, Benjamin Vairel ${ }^{\mathrm{a}}$, Agnès Dupret-Bories ${ }^{\mathrm{a}}$, \\ Stéphane Temam ${ }^{\mathrm{b}}$, Léonor Chaltiel ${ }^{\mathrm{c}}$, Sébastien Vergez ${ }^{\mathrm{a}, *}$ \\ a Department of Surgery, University Cancer Institute Toulouse - Oncopôle, University Hospital of Toulouse, Toulouse, France \\ ${ }^{\mathrm{b}}$ Department of Head and Neck Oncology, Gustave Roussy Institute, University of Paris-Saclay, Villejuif, France \\ ${ }^{\mathrm{c}}$ Biostatistics Unit, Institut Claudius Régaud, Institut Universitaire du Cancer de Toulouse - Oncopole Toulouse, France
}

\section{A R T I C L E I N F O}

Keywords:

Head and neck cancer

Pharyngo-laryngeal squamous cell

carcinoma

Elective neck dissection

Occult lymph node metastasis

Organ preservation

Salvage surgery

\begin{abstract}
A B S T R A C T
Background: Salvage surgeries are challenging procedures, with an associated poor prognosis. Management of the NO neck in those situations remains controversial. We aim to compare oncologic outcomes regarding neck management after surgery for NO pharyngo-laryngeal carcinoma occurring after loco-regional radiotherapy.

Methods: We conducted a multicentric retrospective study, including all patients undergoing surgery for persistent, recurrent or new primary N0 carcinoma of the oropharynx, hypopharynx or larynx between 2005 and 2015, following loco-regional radiotherapy.

Results: A total of 239 patients were included, concerning respectively 44\%, 34\% and 22\% oropharyngeal, laryngeal and hypopharyngeal tumors operated. A neck dissection was performed in 143 patients (60\%), with an occult nodal metastasis rate of $9 \%$. This rate was higher for hypopharyngeal carcinomas (18\%, $\mathrm{p}=0.16)$ and tumors with initial nodal involvement $(16 \%, \mathrm{p}=0.05)$. With a median follow-up of 60 months, the median overall survival (OS) and progression-free survival rates (PFS) were 34 months and 25 months. We identified negative margin excision status, age at the time of surgery (under 60) and delay between RT and surgery over 2 years as the only variables associated with better OS ( $p<0.0001$ and $\mathrm{p}=0.004)$ and PFS $(\mathrm{p}<0.0001$ and $\mathrm{p}=0.010)$ in multivariable analysis, with no difference regarding neck management. Regional progression (alone or with distant metastasis) was noted in 10 cases: 4 in the neck observation group (4\%) versus 6 in the neck dissection group (4\%).

Conclusion: Elective lymph node dissection of irradiated neck should not be routinely performed in patients undergoing surgery for persistent, recurrent or new primary pharyngo-laryngeal carcinomas
\end{abstract}

\section{Introduction}

Despite the development and the improvement, the last decades, of radiotherapy (RT) protocols for the treatment of pharyngeal and laryngeal cancers, situations of recurrent or new primary carcinomas are still frequent [1-3]. Those situations are associated with a poor prognosis, as the 5-year overall survival rate decreases to $20 \%$ [4-8].

Although surgery is today the best chance of cure for these

* Corresponding author. Department of Surgery, University Cancer Institute Toulouse - Oncopôle, University Hospital of Toulouse, 1 Avenue Irène Joliot-Curie, 31059, Toulouse, France.

E-mail address: vergez.s@chu-toulouse.fr (S. Vergez). patients, those "salvage" procedures are associated with an important per and postoperative complication rate, which can lead to major quality of life alterations or even death [9-12]. It is thus important, in those patients presenting with serious comorbidities and pre-existent sequels, to propose a comprehensive approach to their overall burden, by weighing up their chance of cure and the impact on quality of life in the therapeutic proposal $[6,13,14]$.

Thereby, management of the NO neck during surgery occurring after primary RT is still controversial. Nowadays, few studies have reported inhomogeneous results about the benefits of elective neck dissection (ND) in terms of overall survival or loco-regional control in those situations [15]. However, the morbidity associated with this additional procedure is real, considering the negative impact on healing (increased risk of salivary fistulae) and the higher rate of postoperative complications and long term sequels [12,16,17]. 
The objective of our study is to compare the oncologic outcomes of patients undergoing surgery for recurrent, persistent or new primary NO pharyngo-laryngeal cancer after loco-regional RT regarding neck management.

\section{Material and methods}

\section{Study design and patient selection}

This multicentric retrospective study was based on all consecutive cases of oropharyngeal, hypopharyngeal or laryngeal surgery for squamous cell carcinomas performed between 2005 and 2015 in two French tertiary referral centers $(n=2988)$.

We included patients undergoing surgery for NO persistent, recurrent or new primary carcinoma in those locations following a primary treatment including loco-regional RT. We included only cases in which the lymphatic basin of the operated tumor was previously irradiated, meaning that RT concerned at least levels II, III, and IV on the Robbins classification [18]. Cases of prior ND were excluded, as well as T1 carcinomas of the vocal cords considering their poor potential for nodal spread.

\section{Treatment}

Initially, the RT protocol had to deliver at least a dose of $45 \mathrm{~Gy}$ into the lateral neck compartment, on the side of the operated carcinoma (or bilaterally if the tumor crossed the midline). The surgery had to be performed in a curative attempt in patients with no clinical or radiological evidence of lymph node involvement.

The ND were classified as "selective" when concerning levels II, III and IV, "modified radical" when extended to level V (and/or level I) and "supra-selective" when levels IIb or IV were omitted, as reported in the AAO-HNS guideline statements. The central neck compartment (level VI) was not considered in the ND analysis as it owns specific indications and side effects.

A persistent disease was defined as the absence of total macroscopic regression (clinical or radiological) of the tumor after RT. A recurrence was defined as a histology proven SCC on the same location after RT, with at least one examination demonstrating the absence of macroscopic residual disease between the two diagnoses. Any case of tumor on another location was considered as a new primary carcinoma. Regarding tumor resection, positive margins status was defined as excision limits under $1 \mathrm{~mm}$ or in contact with the tumor after pathology. We chose a $3 \mathrm{~mm}$ margin cut-off between close and clear margins, as it permits a better staging between patients with intermediate or high risk of recurrence, according to the local multidisciplinary boards.

The decision whether to perform an ND during surgery was taken by a multidisciplinary board at each center, balancing the expected risk of occult neck metastases with the estimated additional morbidity of the procedure. No standardization of the surgery and the neck treatment decision can be assured upon by the board, as there is no consensual referential regarding this situation.

\section{Data analysis}

The data collected included initial and metachronous cancer characteristics, RT and surgery modalities including the type and extent of neck irradiation and ND, postoperative complications and long-term oncological outcomes. We collected as postoperative complications: salivary fistulae, neck collection or abscess, cervical hematoma, chyle leakage, necessary return to the operating room and death. Paratracheal lymph node metastases were considered as distant progression.

The main outcomes evaluated were overall survival (OS), progression-free survival (PFS) and cumulative incidence of nodal progression between the patients who benefited from a neck dissection (ND group) and those for whom the neck was observed (NO group). The secondary outcomes evaluated were the occult nodal involvement rate in patients who benefited from a ND.

\section{Statistical analysis}

Qualitative variables were summarized as frequencies and percentages for each category, and continuous variables as medians and ranges. Comparisons between groups were assessed using Chisquare or Fisher's exact test for qualitative variables and Kruskal-Wallis test for continuous variables.

All survival times were calculated from the date of surgery. Survival rates were estimated by the Kaplan Meier method using the following first-event definitions: relapse (local, nodal or distant) or death for PFS, and death for OS. Patients event free or alive were censored at the time of their last follow-up. Univariable analyses were performed using the log-rank test. Multivariable analyses were assessed using the Cox proportional hazards model which included clinically relevant factors.

Cumulative incidences of nodal progression (alone or associated with distant metastasis) were estimated using a competing risk methodology (Kalbfleish and Prentice method), which considered other progressions and death as competing events. Comparisons of cumulative incidences between groups were performed using Gray's test in univariable analyses.

All reported p-values were two-sided. Differences were considered significant at a $5 \%$ level.

\section{Results}

Patients and procedures [Table 1]

A total of 239 patients were included, represented by most males (84\%), with a median age of 61 at the time of surgery [Range: 25-88]. Ninety-five percent of them were tobacco smokers and $64 \%$ had excessive alcohol consumption.

The primary treatment with RT was performed for stage T1 or T2 tumors in $50 \%$ of the cases. A nodal involvement was associated with 87 cases (36\%). Most of these procedures (68\%) included a concomitant biotherapy (platine-based chemotherapy or Cetuximab) and were performed with tridimensional conformational RT (70\%).

The salvage surgery was indicated for an oropharyngeal carcinoma in 106 cases (44\%), a laryngeal carcinoma in 81 cases $(34 \%)$ and a hypopharyngeal carcinoma in 52 cases (22\%). The procedure concerned a persistent, recurrent and new primary carcinoma in respectively $19 \%, 47 \%$ and $34 \%$ of cases, with tumors staged $\mathrm{T} 1$ or T2 in $43 \%$ of cases $(n=102)$ and T3 or T4 in $57 \%$ of cases $(n=137)$.

An elective ND was performed in 143 patients (60\%), concerning both sides in 45 cases. The ND $(n=188)$ were classified as modified radical in 29 cases (15\%), selective in 115 cases (61\%) and supraselective in 44 cases (23\%). Regarding the T-stage at surgery, we noted $42 \%$ of T1 or T2 tumors and $58 \%$ of T3 or T 4 tumors, with no difference between the ND and NO groups $(\mathrm{p}=0,78)$. The procedure included a mucosal reconstruction in $56 \%$ cases in the ND group, versus only $38 \%$ in the NO group ( $\mathrm{p}=0.005$ ).

\section{Postoperative outcomes [Tables 2 and 3]}

Regarding the pathology, the final margin status was considered positive in 46 patients (19\%). Among the others, the margins were estimated clear in 125 patients (52\%) and close in 68 patients (29\%). We noted no difference between the NO and ND groups regarding 
Table 1

Patient characteristics $(\mathrm{n}=239)$.

\begin{tabular}{|c|c|c|c|c|}
\hline & Total $(n=239)$ & NO group $(n=96)$ & ND group $(n=143)$ & $p$ value \\
\hline Sex & & & & $p=0.23$ \\
\hline male & $200(84 \%)$ & $77(80 \%)$ & $123(86 \%)$ & \\
\hline female & $39(16 \%)$ & $19(20 \%)$ & $20(14 \%)$ & \\
\hline Age (at time of surgery) & $61[25-88]$ & $63[25-88]$ & $60[40-85]$ & $p=0.02$ \\
\hline \multicolumn{5}{|l|}{ Use history } \\
\hline tabaco & $214(95 \%)$ & 85 (94\%) & $129(95 \%)$ & $p=1.00$ \\
\hline alcohol & $142(64 \%)$ & $52(61 \%)$ & $90(67 \%)$ & $p=0.35$ \\
\hline \multicolumn{5}{|l|}{ RADIOTHERAPY } \\
\hline Location & & & & $p=0.54$ \\
\hline oropharynx & $90(38 \%)$ & $31(32 \%)$ & $59(41 \%)$ & \\
\hline hypopharynx & $51(21 \%)$ & $22(23 \%)$ & $29(20 \%)$ & \\
\hline larynx & $90(38 \%)$ & $39(41 \%)$ & $51(36 \%)$ & \\
\hline other & $8(3 \%)$ & $4(4 \%)$ & $4(3 \%)$ & \\
\hline $\mathrm{N}$ stage & & & & $p=0.03$ \\
\hline No & $143(62 \%)$ & $50(54 \%)$ & $93(68 \%)$ & \\
\hline $\mathrm{N}+$ & $87(36 \%)$ & $43(46 \%)$ & $44(32 \%)$ & \\
\hline NA & 9 & 3 & 6 & \\
\hline Type of radiotherapy & & & & $p=0.39$ \\
\hline exclusive & $77(32 \%)$ & $34(35 \%)$ & $43(30 \%)$ & \\
\hline concurrent chemotherapy & $162(68 \%)$ & $62(65 \%)$ & $100(70 \%)$ & \\
\hline Radiation modality & & & & $p=0.47$ \\
\hline IMRT & $71(30 \%)$ & $26(27 \%)$ & $45(31 \%)$ & \\
\hline 3D CRT & $168(70 \%)$ & $70(73 \%)$ & $98(69 \%)$ & \\
\hline \multicolumn{5}{|l|}{ SURGERY } \\
\hline Location & & & & $p=0.77$ \\
\hline Oropharynx & $106(44 \%)$ & $45(47 \%)$ & $61(43 \%)$ & \\
\hline Hypopharynx & $52(22 \%)$ & $19(20 \%)$ & $33(23 \%)$ & \\
\hline Larynx & $81(34 \%)$ & $32(33 \%)$ & $49(34 \%)$ & \\
\hline Surgery context & & & & $p=0.06$ \\
\hline persistent carcinoma & $46(19 \%)$ & $15(16 \%)$ & $31(22 \%)$ & \\
\hline recurrent carcinoma & $112(47 \%)$ & $40(42 \%)$ & $72(50 \%)$ & \\
\hline new primary carcinoma & $81(34 \%)$ & $41(43 \%)$ & $40(28 \%)$ & \\
\hline T stage & & & & $p=78$ \\
\hline $\mathrm{T} 1-\mathrm{T} 2$ & $102(43 \%)$ & $42(44 \%)$ & $60(42 \%)$ & \\
\hline T3-T4 & $137(57 \%)$ & $54(56 \%)$ & $83(58 \%)$ & \\
\hline
\end{tabular}

3D CRT: three-dimensional conformal radiation therapy.

IMRT: intensity modulated radiation therapy.

the excision margins (23\% of positive margins in the NO group versus $17 \%$ in the ND group, $\mathrm{p}=0.44$ ).

An adjuvant therapy was proposed for 53 patients: $15 \%$ of patients in the NO group versus $27 \%$ of patients in the ND group ( $\mathrm{p}=0.02)$ and consisted of RT in 27 cases, concurrent bio-RT in 22 cases, surgery re-excision in 2 cases and brachytherapy in 2 cases.
The median hospital stay was 19 days in the NO group versus 22 days in the ND group ( $\mathrm{p}=0.004)$ with a postoperative complication rate of $33 \%$ versus $42 \%$ respectively ( $p=0.18$ ). The most important complication was salivary fistulae, occurring in $33 \%$ of cases: $31 \%$ in the NO group and $34 \%$ in the ND group $(\mathrm{p}=0.71)$. We noted 9 cases of postoperative death: $3(3 \%)$ in the NO group versus $6(4 \%)$ in the

Table 2

Postoperative outcomes.

\begin{tabular}{|c|c|c|c|c|}
\hline & Total $(n=239)$ & Neck observation $(n=96)$ & Neck dissection $(n=143)$ & $p$ value \\
\hline Mucosal reconstruction & $116(49 \%)$ & $36(37 \%)$ & $80(56 \%)$ & $p=0.005$ \\
\hline local flap & 4 & 3 & 1 & \\
\hline pedicled flap & 65 & 26 & 39 & \\
\hline free flap & 47 & 7 & 40 & \\
\hline Length of stay (days): median [Range] & $21[3-108]$ & $19[3-84]$ & $22[8-108]$ & $p=0.004$ \\
\hline Post-operative complications & $92(38 \%)$ & $32(33 \%)$ & $60(42 \%)$ & $p=0.18$ \\
\hline salivary fistulae & 78 & 30 & 48 & \\
\hline neck collection & 41 & 17 & 24 & \\
\hline hematoma & 9 & 2 & 7 & \\
\hline chyle leakage & 3 & 0 & 3 & \\
\hline returning to operating room & 44 & 15 & 29 & \\
\hline death & 9 & 3 & 6 & \\
\hline Margin status & & & & $p=0.41$ \\
\hline positive & $46(19 \%)$ & $22(23 \%)$ & $24(17 \%)$ & \\
\hline close $(<3 \mathrm{~mm})$ & $68(29 \%)$ & $24(25 \%)$ & $44(31 \%)$ & \\
\hline clear (>3 mm) & $125(52 \%)$ & $50(52 \%)$ & $75(52 \%)$ & \\
\hline Adjuvant therapy & $53(22 \%)$ & $14(15 \%)$ & $39(27 \%)$ & $p=0.02$ \\
\hline exclusive RT & 27 & 8 & 19 & \\
\hline concurrent bio-RT & 22 & 3 & 19 & \\
\hline surgery & 2 & 1 & 1 & \\
\hline brachytherapy & 2 & 2 & 0 & \\
\hline
\end{tabular}


Table 3

Occult neck metastasis distribution in the ND group.

\begin{tabular}{|c|c|c|c|}
\hline & pN0 group $(n=130)$ & $\mathrm{pN}+\operatorname{group}(n=13)$ & $p$ value \\
\hline \multicolumn{4}{|l|}{ RADIOTHERAPY } \\
\hline Type of radiotherapy & & & $p=0.75$ \\
\hline Exclusive & $31 \%$ & $23 \%$ & \\
\hline Concurrent biotherapy & $69 \%$ & $77 \%$ & \\
\hline Radiation modality & & & $p=1.0$ \\
\hline 3D CRT & $69 \%$ & $69 \%$ & \\
\hline IMRT & $31 \%$ & $31 \%$ & \\
\hline T stage & & & $p=0.62$ \\
\hline $\mathrm{T} 1 / \mathrm{T} 2$ & $49 \%$ & $42 \%$ & \\
\hline $\mathrm{T} 3 / \mathrm{T} 4$ & $51 \%$ & $58 \%$ & \\
\hline \multicolumn{4}{|l|}{ (unknown stage for 13 patients) } \\
\hline $\mathrm{N}$ stage & & & $p=0.05$ \\
\hline NO & $70 \%$ & $42 \%$ & \\
\hline $\mathrm{N}+$ & $30 \%$ & $58 \%$ & \\
\hline \multicolumn{4}{|l|}{ (unknown stage for 9 patients) } \\
\hline \multicolumn{4}{|l|}{ SURGERY } \\
\hline Location & & & $p=0.16$ \\
\hline Oropharynx & $44 \%$ & $31 \%$ & \\
\hline Hypopharynx & $21 \%$ & $46 \%$ & \\
\hline Larynx & $35 \%$ & $23 \%$ & \\
\hline Surgery context & & & $p=0.86$ \\
\hline Persistent carcinoma & $22 \%$ & $15 \%$ & \\
\hline Recurrent carcinoma & $50 \%$ & $54 \%$ & \\
\hline New primary carcinoma & $28 \%$ & $31 \%$ & \\
\hline Radiologic assessment & & & $p=0.76$ \\
\hline MRI & $30 \%$ & $23 \%$ & $p=0.55$ \\
\hline PET & $35 \%$ & $46 \%$ & \\
\hline T stage & & & $p=0.74$ \\
\hline $\mathrm{T} 1 / \mathrm{T} 2$ & $42 \%$ & $46 \%$ & \\
\hline T3/T4 & $58 \%$ & $54 \%$ & \\
\hline
\end{tabular}

3D CRT: three-dimensional conformal radiation therapy.

IMRT: intensity modulated radiation therapy.

MRI: magnetic resonance imaging.

PET: positron emission tomography

ND group $(p=0.74)$. Four cases of death were linked to massive hemorrhages secondary to salivary fistulae, 3 of which (75\%) benefited from an ND.

Occult nodal metastases were noted in 13 patients (9\%) among the entire ND group. It concerned a single node for 6 patients, multiples nodes for 7 patients and an extra-capsular nodal spread were noted in 7 patients (54\%). Occult metastasis rate was estimated at $6 \%$ for laryngeal carcinomas, $7 \%$ for oropharyngeal carcinomas and $18 \%$ for hypopharyngeal carcinomas $(\mathrm{p}=0.16)$. It concerned level IIa and III in most cases, as level IIb and IV were involved in only 2 cases (out of 172 and 148 dissected levels respectively).

In our exploratory analysis, occult nodal metastases affected more likely patients with positive $\mathrm{N}$ stage at the time of RT, as it reached $16 \%$ for these patients.

Otherwise, tumor sub-location, T stage (initial and at surgery), context of surgery (persistent, recurrent or new primary carcinoma), RT modalities and delay between radiotherapy and surgery were not associated with presence of occult nodal metastasis.

\section{Oncologic outcomes [Figs. 1 and 2]}

With a median follow-up of 60 months after surgery, we noted a relapse of the carcinoma in 115 cases (48\%). It consisted of local progression in most of the cases ( $n=86,75 \%$ ), including 14 cases of new primary carcinoma. We observed 26 cases of nodal progression (12 in the NO group versus 14 in the ND group), 16 of which (62\%) were associated with a new local progression, while isolated nodal progression occurred in 10 cases: 4 in the NO group versus 6 in the ND group.

Among the 75 patients who presented a progression without distant metastasis (local and/or nodal), only 27\% were able to benefit from salvage procedure (by surgery or RT).

The median overall survival (OS) and median progression-free survival (PFS) were estimated at 34 months (95\%IC [27-48]) and 25 months (95\%IC [16-34]) respectively. We noted no difference between the NO and ND groups regarding the OS and PFS in univariable and multivariable analysis (OS HR 0.91 [0.65-1.28] and PFS HR 0.91 [0.65-1.27] for the ND group in multivariable analysis). Age at surgery (patients under 60), delay between RT and surgery over 2 years and laryngeal carcinomas were associated with better OS $(\mathrm{p}=0.002, \mathrm{p}=0.03$ and $\mathrm{p}=0.05$ respectively $)$ and PFS $(\mathrm{p}=0.01$, $\mathrm{p}=0.08$ and $\mathrm{p}=0.09$ ), and positive excision margins were associated with worst outcomes ( $p<0.0001$ in OS and PFS) [Table 4].

Patients with laryngeal carcinomas had the best survival outcomes with respectively median OS and PFS of 67 months (95\%IC [30-97]) and 51 months (95IC [25-90]), versus 33 (95\%IC [21-48]) and 21 months (95\%IC [13-35]) for oropharyngeal carcinomas and 27 (95\%IC [18-38]) and 16 months (95\%IC [13-33]) for hypopharyngeal carcinomas. In the separate analysis of the different locations, we noted no difference in OS and PFS between the NO and the ND groups.

Regarding the regional control rate, we noted a $3.4 \%$ cumulative incidence of nodal progression at 2 years [1.6-6.3] versus a $45.8 \%$ cumulative incidence of other event [39-52], with no difference between the NO and ND groups.

\section{Discussion}

Since the first reports of Burge and Jonsson using lymphangiography to assess lymphatic changes after irradiation, it has been well established that over $40 \mathrm{~Gy}$, the lymphatic vessels and nodes 


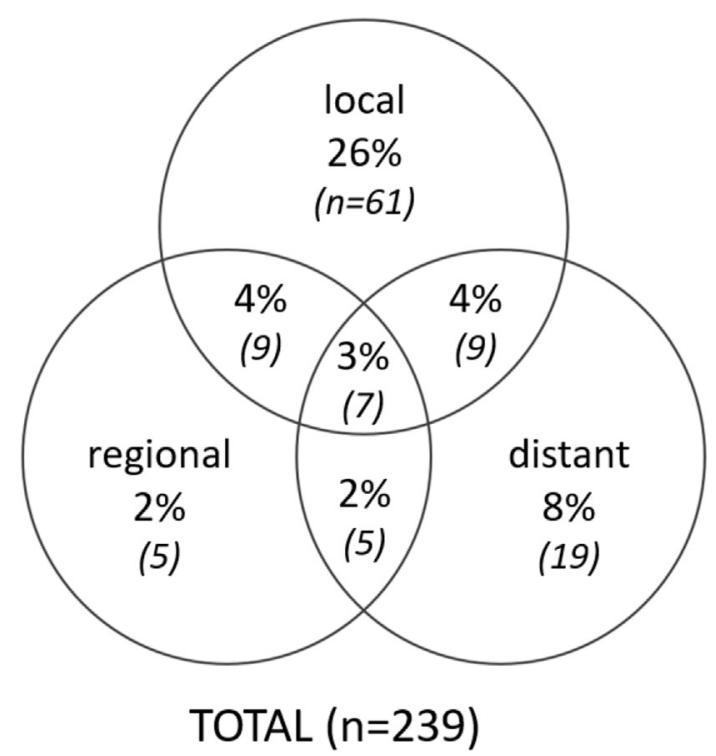

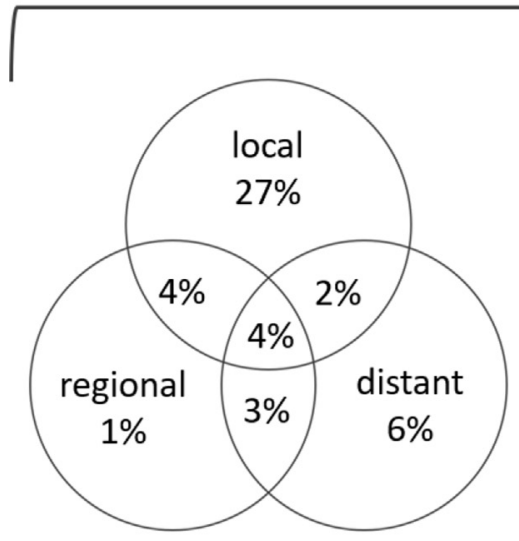

NECK OBSERVATION GROUP

$(n=96)$

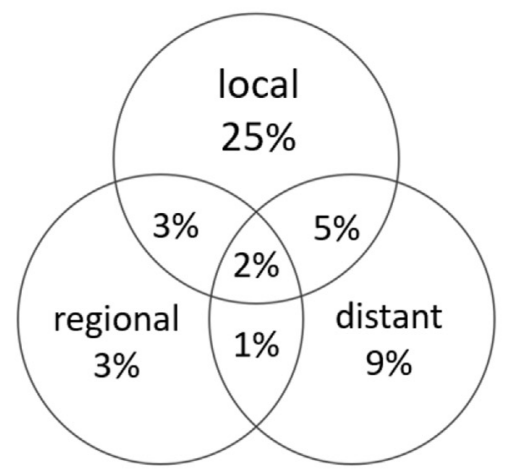

NECK DISSECTION GROUP

$(n=143)$

Fig. 1. Relapse distribution.

become hyalinized and fibrosed [19,20]. In their time, the authors were the first to raise the possibility that these changes may serve as a barrier for lymphatic dissemination of locally recurrent tumors after previous irradiation. However, the standard of care for neck management in case of salvage surgery after RT is still not established, with no consensual guidelines nowadays [21,22].

In the literature, most of the published series concern salvage total laryngectomy, with a wide range of occult nodal metastasis rates, from 0 to $30 \%$ according to a recent review by Silverman, in which most of the series didn't differentiate central and lateral ND (while those procedures have different issues in our opinion) or didn't report irradiation data (probably including cases of limited glottic irradiation with no nodal prophylaxis) $[23,24]$. When the salvage procedure was extending to all head and neck locations, the occult metastasis rate ranged from $3 \%$ to $12 \%$ in recurrent carcinomas presenting with NO neck at both initial and recurrence and up to $22 \%$ in initially positive necks according to Prendes in a case series of 16 patients [15,25].

In our series, we report a low overall rate of occult nodal metastasis, with no association with the T stage at surgery. Still, we identified two high-risk situations regarding their occult nodal metastasis potential: initial nodal involvement at the time of RT and hypopharyngeal carcinomas, although whether or not an ND was performed in those situations did not affect survival outcomes. Thus, it appears the occult nodal metastasis rate may not be an efficient indicator for neck management. Besides, we observe in the literature inhomogeneous results among retrospective series, which explains why the cut-off value remains controversial since the first decision-analysis model published in 1994 by Weiss, which concluded that elective NDs should be performed for patients with a suspected occult nodal metastasis rate higher than $20 \%$. For example, some have proposed different values, by arguing that the data Weiss used in their algorithm have evolved, such as the better initial nodal staging and the higher salvage rate in case of recurrence $[26,27]$. Hilly published recently their own decision-analysis model for salvage laryngectomy, according to which routine elective ND was not recommended [28]. In our opinion, relying on survival outcomes could be a more relevant indicator than the occult metastasis rate, which has different significations and clinical issues in salvage surgery than in upfront surgery.

Although retrospective, our series report no benefit of elective ND in survival rates, without significant difference between the NO and ND groups. In fact, the prognostic of these patients is likely to be linked to the local control, as we report an important rate of local 

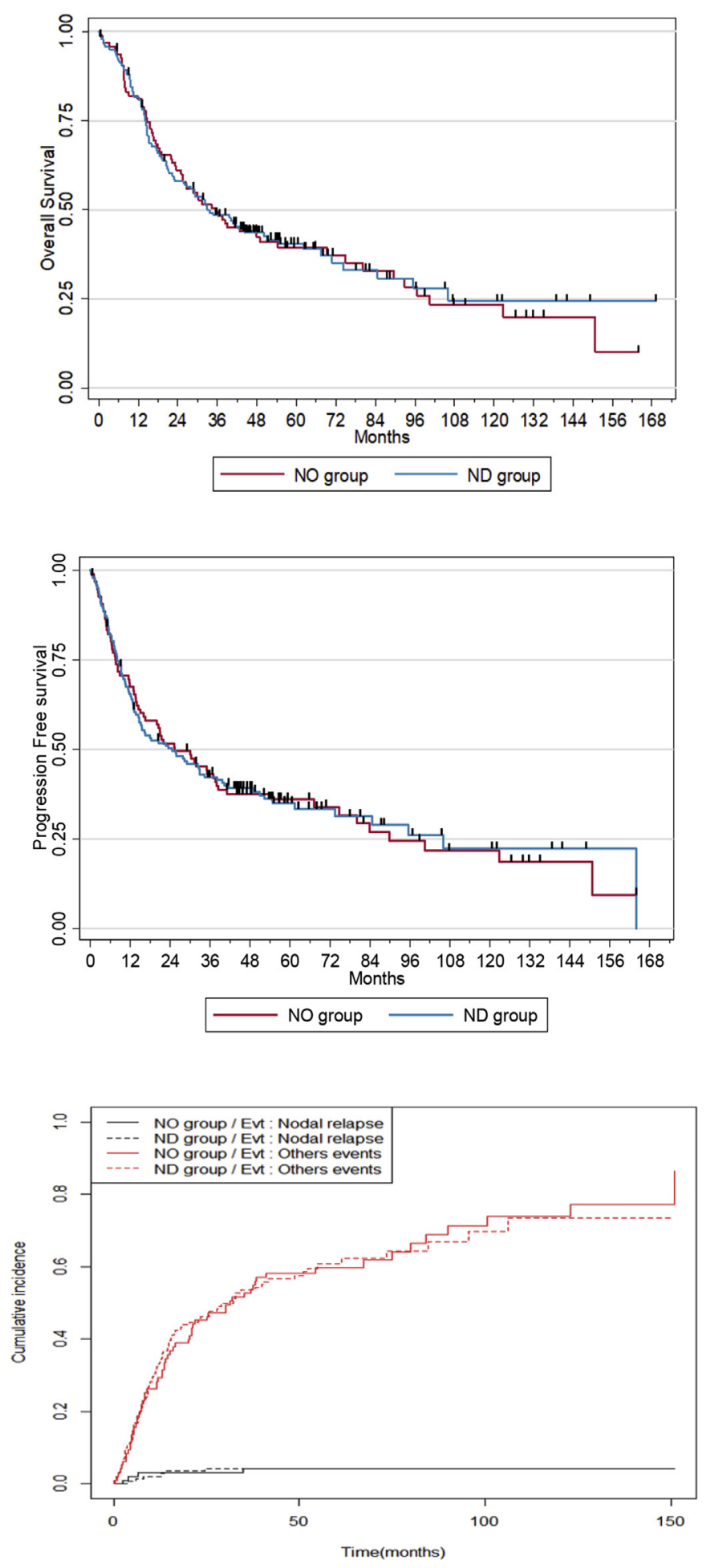

Fig. 2. Overall survival, progression-free survival and cumulative incidence of nodal progression (alone or associated with distant metastasis) curves.

tumor progression (36\%) in our series with a very low salvage rate in those new progressions. In fact, this rate seems closely linked to the important insufficient or limited margin resection rate (of $48 \%$ in our series), which illustrates the difficulty of those salvage procedures, and so the necessity to focus on the tumor resection quality, with clinical excision margins over 1 or $2 \mathrm{~cm}$ during surgery.
Table 4

Hazard Ratio for overall survival and progression-free survival (in multivariable analysis)

\begin{tabular}{|c|c|c|c|c|}
\hline & \multicolumn{2}{|c|}{ OVERALL SURVIVAL } & \multicolumn{2}{|c|}{$\begin{array}{l}\text { PROGRESSION-FREE } \\
\text { SURVIVAL }\end{array}$} \\
\hline \multicolumn{5}{|l|}{ T stage at surgery } \\
\hline $\mathrm{T} 1 / \mathrm{T} 2$ & 1 & - & 1 & - \\
\hline T3/T4 & 1.05 & $p=0.78$ & 1,16 & $p=0.42$ \\
\hline \multicolumn{5}{|l|}{$\mathrm{N}$ stage before radiotherapy } \\
\hline NO & 1 & - & 1 & - \\
\hline $\mathrm{N}+$ & 1.03 & $p=0.87$ & 1.00 & $p=0.98$ \\
\hline \multicolumn{5}{|l|}{ Context of surgery } \\
\hline persistent carcinoma & 1 & - & 1 & - \\
\hline recurrent carcinoma & 0.96 & $p=0.87$ & 0.83 & $p=0.43$ \\
\hline new primary carcinoma & 0.86 & $p=0.61$ & 0.85 & $p=0.59$ \\
\hline \multicolumn{5}{|l|}{ Limits of excision } \\
\hline $\mathrm{RO}$ (close or clear margins) & 1 & - & 1 & - \\
\hline $\mathrm{R} 1$ (positive margins) & 3.48 & $p<0.0001$ & 3.39 & $p<0.0001$ \\
\hline \multicolumn{5}{|l|}{ Location } \\
\hline oropharynx & 0.72 & $p=0.13$ & 0.84 & $p=0.41$ \\
\hline hypopharynx & 1 & - & 1 & - \\
\hline larynx & 0.61 & $p=0.05$ & 0.66 & $p=0.09$ \\
\hline \multicolumn{5}{|l|}{ Neck dissection } \\
\hline no & 1 & - & 1 & - \\
\hline yes & 0.92 & $p=0.64$ & 0.92 & $p=0.61$ \\
\hline \multicolumn{5}{|l|}{ Age at surgery } \\
\hline$<60$ years & 1 & - & 1 & - \\
\hline$>60$ years & 1.72 & $p=0.002$ & 1.57 & $p=0.01$ \\
\hline \multicolumn{5}{|l|}{ Delay between RT and surgery } \\
\hline$<2$ years & 1 & - & 1 & - \\
\hline$>2$ years & 0.63 & $p=0.03$ & 0.69 & $p=0,08$ \\
\hline
\end{tabular}

Moreover, the absence of benefit of ND is highlighted by the fact that among the 10 patients who developed a nodal progression (alone or with distant metastasis), most belonged to the ND group $(n=6)$. Those results are particularly surprising given that the ND group seems to have been treated more aggressively, with a lower rate of insufficient margin resections at pathology (17 versus $23 \%$ for the NO group, $\mathrm{p}=0,24)$ and with more adjuvant treatments after surgery ( 28 versus $15 \%, \mathrm{p}=0,02$ ).

Concerning the additional morbidity of neck dissection, its impact is now well documented, with long term sequels dominated by cervical and shoulder dysfunction [16,29-31]. In a RTOG prospective trial evaluating late toxicity after chemoradiation for advanced head and neck carcinoma, secondary neck dissection was significantly associated with moderate and severe late toxicity (chronic laryngeal or pharyngeal toxicity grade $>3$, organ dysfunction or death) in multivariable analysis [32]. When coupled to the tumor resection, it appeared that ND was associated with a higher rate of postoperative complication rate in salvage laryngectomy or pharyngo-laryngectomy, which were dominated by salivary fistulae, according to two recent meta-analyses $[33,34]$.

In our series, we report a complication rate similar to the literature, dominated by salivary fistula, without significant differences between the NO and ND groups. However, we did not quantify the importance of the fistula, which can be directly associated with the morbi-mortality in the postoperative period, as we reported 3 cases of death secondary to carotid blowout in the ND group, versus 1 in the NO group. We noted a significant longer hospital stay in the ND group, but we reported also more mucosal reconstructions in the ND group. The similar postoperative outcomes may be partly explained by the limited extent of ND when performed, with selective or supra-selective ND in more than $80 \%$ cases, as the complication rate seems to be directly linked to the extent of the dissection, according to Van Den Bovenkamp [17].

Nowadays, with the recent advent of transoral robotic surgery (TORS) demonstrating the functional benefits of avoiding cervicotransoral communication in pharyngo-laryngeal procedures, 
indications have developed and TORS is now well described for salvage procedures [35]. In our opinion, those minimal invasive procedures would particularly benefit from keeping their neck unexplored in term of functional outcomes. In contrast, when a free flap is necessary, an access to the neck is needed for anastomosis and the dissection of the vascular axis may justify a neck exploration, which should be as selective as possible. Indeed, occult nodal metastasis were noted outside level IIa or III in only three cases in our series, thereby raising the possibility of performing supraselective ND, which could lead to better functional outcomes, notably on shoulder dysfunction by omitting level IIb.

\section{Conclusion}

Elective neck dissection should not be routinely performed in patients undergoing surgery for persistent, recurrent or new primary NO pharyngo-laryngeal carcinoma after radiotherapy considering the low rate of occult nodal metastasis and the lack of survival benefit.

In our opinion, elective lymph node dissection in irradiated neck can be weighed up for high-risk tumors (hypopharyngeal carcinomas or persistent carcinomas with initial nodal involvement) or when a free flap is considered, but it can be limited to level Ila and III.

\section{Declaration of competing interest}

None

\section{Acknowledgments}

None.

\section{References}

[1] Lefebvre J-L, Andry G, Chevalier D, et al. Laryngeal preservation with induction chemotherapy for hypopharyngeal squamous cell carcinoma: 10 -year results of EORTC trial 24891. Ann Oncol 2012;23(10):2708-14. https://doi.org/ 10.1093/annonc/mds065.

[2] Forastiere AA, Goepfert H, Maor M, et al. Concurrent chemotherapy and radiotherapy for organ preservation in advanced laryngeal cancer. $\mathrm{N}$ Engl Med 2003;349(22):2091-8. https://doi.org/10.1056/NEJMoa031317.

[3] Mendenhall WM, Amdur RJ, Stringer SP, Villaret DB, Cassisi NJ. Radiation therapy for squamous cell carcinoma of the tonsillar region: a preferred alternative to surgery? J Clin Oncol 2000;18(11):2219-25. https://doi.org/ 10.1200/JCO.2000.18.11.2219.

[4] Marur S, Forastiere AA. Head and neck cancer: changing epidemiology, diagnosis, and treatment. Mayo Clin Proc 2008;83(4):489-501. https:// doi.org/10.4065/83.4.489.

[5] Brockstein B, Haraf DJ, Rademaker AW, et al. Patterns of failure, prognostic factors and survival in locoregionally advanced head and neck cancer treated with concomitant chemoradiotherapy: a 9-year, 337-patient, multiinstitutional experience. Ann Oncol 2004;15(8):1179-86. https://doi.org 10.1093/annonc/mdh308.

[6] Goodwin WJ. Salvage surgery for patients with recurrent squamous cell carcinoma of the upper aerodigestive tract: when do the ends justify the means? The Laryngoscope 2000;110(3 Pt 2 Suppl 93):1-18. https://doi.org/10.1097/ 00005537-200003001-00001.

[7] León X, Quer M, Diez S, Orús C, López-Pousa A, Burgués J. Second neoplasm in patients with head and neck cancer. Head Neck 1999;21(3):204-10.

[8] Chuang S-C, Scelo G, Tonita JM, et al. Risk of second primary cancer among patients with head and neck cancers: a pooled analysis of 13 cancer registries. Int J Cancer 2008;123(10):2390-6. https://doi.org/10.1002/ijc.23798.

[9] Tibbs MK. Wound healing following radiation therapy: a review. Radiother Oncol 1997;42(2):99-106.

[10] Ganly I, Patel S, Matsuo J, et al. Postoperative complications of salvage total laryngectomy. Cancer 2005;103(10):2073-81. https://doi.org/10.1002/ cncr.20974.

[11] van der Putten L, de Bree R, Kuik DJ, et al. Salvage laryngectomy: oncologica and functional outcome. Oral Oncol 2011;47(4):296-301. https://doi.org 10.1016/j.oraloncology.2011.02.002.

[12] Basheeth N, O'Leary G, Sheahan P. Pharyngocutaneous fistula after salvage laryngectomy: impact of interval between radiotherapy and surgery, and performance of bilateral neck dissection. Head Neck 2014;36(4):580-4. https://doi.org/10.1002/hed.23337.

[13] Pang L, Jeannon J-P, Simo R. Minimizing complications in salvage head and neck oncological surgery following radiotherapy and chemo-radiotherapy. Curr Opin Otolaryngol Head Neck Surg 2011;19(2):125-31. https://doi.org/ 10.1097/MOO.0b013e3283440ee3.

[14] Ho AS, Kraus DH, Ganly I, Lee NY, Shah JP, Morris LGT. Decision making in the management of recurrent head and neck cancer. Head Neck 2014;36(1): 144-51. https://doi.org/10.1002/hed.23227.

[15] Sanabria A, Silver CE, Olsen KD, et al. Is elective neck dissection indicated during salvage surgery for head and neck squamous cell carcinoma? Eur Arch Oto-Rhino-Laryngol 2014;271(12):3111-9. https://doi.org/10.1007/s00405014-2893-X.

[16] Ahlberg A, Nikolaidis P, Engström T, et al. Morbidity of supraomohyoidal and modified radical neck dissection combined with radiotherapy for head and neck cancer: a prospective longitudinal study. Head Neck 2012;34(1):66-72. https://doi.org/10.1002/hed.21689.

[17] van den Bovenkamp K, Noordhuis MG, Oosting SF, et al. Clinical outcome of salvage neck dissections in head and neck cancer in relation to initial treatment, extent of surgery and patient factors. Clin Otolaryngol 2017;42(3): 693-700. https://doi.org/10.1111/coa.12818.

[18] Robbins KT, Shaha AR, Medina JE, et al. Consensus statement on the classification and terminology of neck dissection. Arch Otolaryngol Head Neck Surg 2008;134(5):536. https://doi.org/10.1001/archotol.134.5.536.

[19] Burge JS. Histological changes in cervical lymph nodes following clinical irradiation. Proc R Soc Med 1975;68(2):77-9.

[20] Jonsson K, Libshitz HI, Osborne BM. Lymphangiographic changes after radiation therapy. AJR Am J Roentgenol 1978;131(5):803-6. https://doi.org/ 10.2214/ajr.131.5.803.

[21] Thariat J, Hamoir M, Garrel R, et al. Management of the neck in the setting of definitive chemoradiation: is there a consensus? A GETTEC study. Ann Surg Oncol 2012;19(7):2311-9. https://doi.org/10.1245/s10434-012-2275-9.

[22] McSpadden R, Zender C, Eskander A. AHNS series: do you know your guidelines? Guideline recommendations for recurrent and persistent head and neck cancer after primary treatment. Head Neck 2018. https://doi.org/10.1002/ hed.25443.

[23] Silverman DA, Puram SV, Rocco JW, Old MO, Kang SY. Salvage laryngectomy following organ-preservation therapy - an evidence-based review. Oral Oncol 2019;88:137-44. https://doi.org/10.1016/j.oraloncology.2018.11.022.

[24] Birkeland AC, Rosko AJ, Issa MR, et al. Occult nodal disease prevalence and distribution in recurrent laryngeal cancer requiring salvage laryngectomy. Otolaryngology-Head Neck Surg (Tokyo) 2016;154(3):473-9. https://doi.org/ 10.1177/0194599815627811.

[25] Prendes BL, Aubin-Pouliot A, Egbert N, Ryan WR. Elective lymphadenectomy during salvage for locally recurrent head and neck squamous cell carcinoma after radiation. Otolaryngol Head Neck Surg 2014;151(3):462-7. https:// doi.org/10.1177/0194599814537444.

[26] Weiss MH, Harrison LB, Isaacs RS. Use of decision analysis in planning a management strategy for the stage NO neck. Arch Otolaryngol Head Neck Surg 1994;120(7):699-702. https://doi.org/10.1001/ archotol.1994.01880310005001.

[27] Okura M, Aikawa T, Sawai NY, Iida S, Kogo M. Decision analysis and treatment threshold in a management for the NO neck of the oral cavity carcinoma. Oral Oncol 2009;45(10):908-11. https://doi.org/10.1016/ j.oraloncology.2009.03.013.

[28] Hilly O, Stern S, Horowitz E, Leshno M, Feinmesser R. Is there a role for elective neck dissection with salvage laryngectomy? A decision-analysis model. The Laryngoscope 2013;123(11):2706-11. https://doi.org/10.1002/ lary.24138.

[29] Kuntz AL, Weymuller EA. Impact of neck dissection on quality of life. The Laryngoscope 1999;109(8):1334-8. https://doi.org/10.1097/00005537199908000-00030.

[30] Watkins JP, Williams GB, Mascioli AA, Wan JY, Samant S. Shoulder function in patients undergoing selective neck dissection with or without radiation and chemotherapy. Head Neck 2011;33(5):615-9. https://doi.org/10.1002/ hed.21503.

[31] Gane EM, Michaleff ZA, Cottrell MA, et al. Prevalence, incidence, and risk factors for shoulder and neck dysfunction after neck dissection: a systematic review. Eur J Surg Oncol 2017;43(7):1199-218. https://doi.org/10.1016/ j.ejso.2016.10.026.

[32] Machtay M, Moughan J, Trotti A, et al. Factors associated with severe late toxicity after concurrent chemoradiation for locally advanced head and neck cancer: an RTOG analysis. J Clin Oncol 2008;26(21):3582-9. https://doi.org/ 10.1200/JCO.2007.14.8841.

[33] Hasan Z, Dwivedi RC, Gunaratne DA, Virk SA, Palme CE, Riffat F. Systematic review and meta-analysis of the complications of salvage total laryngectomy. Eur J Surg Oncol 2017;43(1):42-51. https://doi.org/10.1016/ j.ejso.2016.05.017.

[34] Paydarfar JA, Birkmeyer NJ. Complications in head and neck surgery: a metaanalysis of postlaryngectomy pharyngocutaneous fistula. Arch Otolaryngol Head Neck Surg 2006;132(1):67-72. https://doi.org/10.1001/ archotol.132.1.67.

[35] Meulemans J, Vanclooster C, Vauterin T, et al. Up-front and salvage transoral robotic surgery for head and neck cancer: a Belgian multicenter retrospective case series. Front Oncol 2017;7:15. https://doi.org/10.3389/fonc.2017.00015. 